\title{
Epidemiology of amyotrophic lateral sclerosis patients in a centre in Buenos Aires
}

\author{
Mariela Bettini ${ }^{1}$, Gisella M. Gargiulo-Monachelli1,2, Gabriel Rodríguez', \\ Raul C. Rey', Liliana Martinez Peralta ${ }^{4}$, Roberto E.P. Sica ${ }^{3}$
}

\begin{abstract}
Sporadic amyotrophic lateral sclerosis (sALS) is considered a multifactorial disease with genetic and environmental factors causing motor neuron degeneration. Objective: To describe the epidemiological and occupational characteristics of patients with SALS who attended the Ramos Mejía Hospital at Buenos Aires, Argentina. Method: We analyzed the medical records of sALS patients diagnosed between 2001 and 2008. All occupations were coded according to the International Standard Classification of Occupation (ISCO). Results: 187 patients were assessed, 38.5\% were women and 61.5\% men. Mean age at diagnosis was 55 years. $16 \%$ of them came from rural areas; $68 \%$ of the studied population had no health insurance. $40 \%$ were employed in elementary occupations, 19 were technicians and 8 handicraftsmen. Conclusion: The most represented profession was elementary occupation. A large proportion of patients came from rural areas, which might suggest an increased risk of environmental exposure to an unknown agent in those regions. Key words: ALS, sALS, risk factor, epidemiology, occupation.
\end{abstract}

\section{Epidemiología de los pacientes con esclerosis lateral amiotrófica en el centro de Buenos Aires}

\section{RESUMEN}

La esclerosis lateral amiotrófica esporádica (ELAe) es considerada una enfermedad multifactorial. Objetivo: Describir las características epidemiológicas y laborales de un grupo de pacientes con ELAe que fueron evaluados en el Hospital Ramos Mejía de Buenos Aires, Argentina. Método: Se analizaron los registros médicos de pacientes con ELAe diagnosticados entre 2001 y 2008. Las ocupaciones fueron codificadas de acuerdo a la Clasificación Internacional de Ocupaciones (ISCO). Resultados: 187 pacientes fueron evaluados, 38,5\% mujeres y 61,5\% hombres. Edad media al diagnóstico 55 años. $16 \%$ procedían de zonas rurales, $68 \%$ no tenía seguro de salud. $40 \%$ se encontraba empleado en ocupaciones elementales, $19 \%$ eran técnicos, $8 \%$ artesanos y $7 \%$ operadores de maquinas. Conclusión: La profesión más representada fue la de ocupación elemental. Una gran proporción de los pacientes provenían de zonas rurales, lo que podría sugerir un mayor riesgo de exposición ambiental a un agente desconocido en esas regiones.

\section{Correspondence \\ Mariela Bettini \\ Department, J.M. Ramos Mejía Hospital Urquiza 609 (postal code 1221ADC) \\ Ciudad Autónoma de \\ Buenos Aires, Argentina \\ E-mail: marielabettini@yahoo.com.ar}

Conflicts of interest

The authors report no

conflicts of interest

Received 15 June 2011

Received in final form 25 July 2011

Accepted 1 August 2011

Palabras-Clave: ELA, ELAe, factor de riesgo, epidemiología, ocupación.

Sporadic amyotrophic lateral sclerosis (sALS) is a progressive neurodegenerative disease that affects upper and lower motor neurons.
Its frequency is relatively uniform throughout the world, with a calculated incidence and prevalence of 1.5-2.6/100,000/ year and 0.8-8.5/100,000, respectively.

${ }^{1}$ Neurology Department, J.M. Ramos Mejía Hospital, School of Medicine, University of Buenos Aires, Argentina; ${ }^{2}$ Instituto de Biología y Medicina Experimental (IBYME-CONICET), Buenos Aires, Argentina; ${ }^{3}$ Science and Technology Department, School of Medicine, Buenos Aires University, Buenos Aires, Argentina; ${ }^{4}$ Microbiology Department, School of Medicine, Buenos Aires, Argentina. 
The incidence ranges between 0.31, in Japan, and 2.6, in Sweden, per 100,000 persons/year, with the exception of some Western Pacific regions, where a higher incidence does exist ${ }^{1}$. Variation in reported incidences has been attributed either to the small size of study populations or to differences in case ascertainment.

sALS affects males more often than females, the ratio being 1.2-2.6/1. The disease usually appears between 50 and 60 years of age, varying the average survival time between 3 and 5 years. sALS presents clinically with either bulbar or spinal onset, the latter being the most common form ${ }^{2}$. sALS is considered to be a multifactorial disease with multiple genetic and environmental factors causing motor neuron degeneration ${ }^{3}$. Some potential risk factors have been implicated, but its aetiology remains unknown ${ }^{4}$.

Epidemiological studies have shown an increased incidence of sALS in people inhabiting rural areas, a feature which suggest either a potential role for the exposure to agricultural chemicals or contact with cattle or other animals linked to agricultural work.

Occupation has been suggested, as well, to play a role in sALS aetiology $y^{5}$, but detailed information on the importance of specific workplace exposures is lacking. Work history often serves as a surrogate for a variety of environmental exposures and can be studied more easily than actual exposure to specific toxic substances, radiation or other exogenous agents ${ }^{5}$.

Evaluation of the occurrence of sALS within occupational groups could provide clues for elucidating the aetiology and underlying pathogenic processes of the disease.

The aim of this study was to, retrospectively, describe the epidemiological and the occupational characteristics in a serie of patients with sALS.

\section{METHOD}

We consecutively reviewed the medical records of patients who received the diagnosis of definite and probable sALS, according to the El Escorial criteria ${ }^{6}$ from January 2001 to December2008, who attended the Motoneuron Disease Referral Centre at the Ramos Mejía Hospital, Buenos Aires.

We analyzed: gender, mean age at diagnosis, spinal or bulbar type of onset by gender, place and area of residence (urban or rural areas), health insurance status (private, work-related, public or none) and occupation in accordance to the International Standard Clasification of Occupation (ISCO) ${ }^{7}$.

Furthermore, we obtained information about all out- patients clinics assessments done in the Neurology Department of the Ramos Mejía Hospital from January to December, $2008^{8}$, to estimate sALS incidence in our Institution.

\section{RESULTS}

At the Ramos Mejía Hospital, from January to December 2008, the annual whole incidence of neurological diseases was 733 per 100,000 patients.

Patients were assessed in the out-patients clinics of the Institution. sALS incidence was 6 per 100,000 (0.8\%) people along that year.

On the other hand, we reviewed 187 medical records of patients whose diagnosis of definitive or probable sALS was achieved following the El Escorial criteria; 61.5 $(n=115)$ were males and $38.5 \%(n=72)$ were females. The age, at diagnosis, in men and women (mean \pm standard deviation (range)) was $58 \pm 11$ (26-86) and 53 \pm 13 (22-79) years respectively, with a male/female ratio of 1.59 . In men the presentation of the disease was spinal in $77.4 \%$ and bulbar in $22.6 \%$ of them. In women onset was $61 \%$ spinal and 39\% bulbar. Eighty four percent of our patients came from urban areas, while 16 of them originated within rural areas.

We observed that $88 \%$ of sALS patients who attended our Centre lived in remote areas, far from the Hospital, only $16 \%$ of them came from downtown Buenos Aires city. Sixty eight percent of the patients had no health insurance (they were attached to the public health services), while 32 of them had some kind of private, workrelated or public health insurance.

Analysis of work activities, according to the International Standard Clasification of Occupation (ISCO) (Table), revealed that most of sALS patients belonged to Group 9 (elementary occupations), followed by Group 3 (technicians). The Groups 7, 8 and 2 (craft and related trades workers, plant and machine operators and assemblers and professionals, respectively) have a similar proportion of sALS patients. No data, in this regard, was available in $16 \%$ of the population (Figure).

\section{DISCUSSION}

The incidence of sALS is considered to be about 0.6 to $2.5 / 100,000$ in the general population. Variations have been reported, these divergences might be attributed to the fact that the reported series were obtained at different regions and, also, to the variability of population samples sizes ${ }^{9-11}$.

Between January and December 2008, we recorded a Ramos Mejía hospital sALS incidence of 6 per 100,000, assessed at the out-patient clinic. It represents $0.006 \%$ of all the general medical assessments done along that year and $0.8 \%$ of the neurological assessments.

Our Hospital is a public Institution, located at Buenos Aires city, which is inhabited by $3,000,000$ people, which provides free health services to the whole population (with and without social security/health insurance). We attribute the high incidence that we found in our Institu- 
Table. International Standard Clasification of Occupation (ISCO).

\begin{tabular}{cl}
\hline Group & \\
\hline 1 & Managers \\
2 & Professionals \\
3 & Technicians and associate proffessionals \\
4 & Clerical support workers \\
5 & Service and sales workers \\
6 & Skilled agricultural, forestry and fishery workers \\
7 & Craft and related trades workers \\
8 & Plant and machine operators and assemblers \\
9 & Elementary occupations \\
0 & Armed forces occupations \\
\hline
\end{tabular}

tion to the fact that we have a motoneuron disease reference Centre, so many patients are referred to us, whether they live or not within the influence area of the Hospital.

With regard to age, gender and clinical presentation of the disease, our findings are similar to those published by other authors ${ }^{12,13}$. Interestingly, mean age at diagnosis from specialized centres is lower (approximately by 10 years) than mean age derived from population studies ${ }^{14}$. We could appreciate this fact in our series as well, which may be due to the higher degree of training, in this particular disease, of the physicians working in referral Centres. Other effect to be considered, for explaining this behaviour, is that most of the population based studies in the literature gathered data from death certificates and registers ${ }^{15}$, where an underestimation of occurrence of the disease usually exists.

In the analysis of the geographical origin of our patients, we found that most of them came from remote areas, far from the influential zone of the hospital; and only 12 of sALS patients who attended our centre were from the Buenos Aires city. This can be explained by the lack of specialized and multidisciplinary clinics outside de city, so patients who come from other cities by their own or referred by other physicians, approach our Centre to optimize their treatment and management.

We have analyzed health insurance state of our patients as an indicator of their socioeconomic status. We observed that more than half of them have not any health insurance. This finding suggests that most of our patients belong to a low income socioeconomic class.

Indeed, we observed that a great proportion of sALS patients who assist to our Centre lives in rural areas. Rural environment was proposed, in some series ${ }^{16,17}$, as a risk factor for sALS, due to the eventual exposure to different toxic substances which are handled in farms working activities. So, a strong association was found between agricultural activity and sALS, while rural residence, by itself, did not influence the risk of the dis-

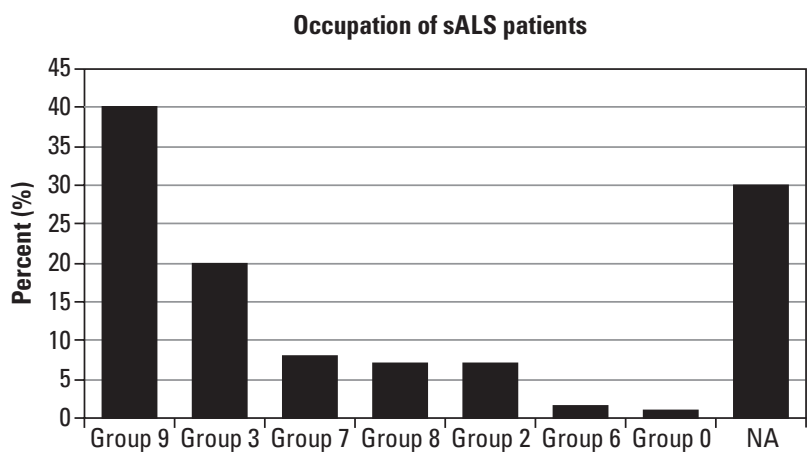

sALS: Sporadic Amyotrophic Lateral Sclerosis; ISCO: International Standard Clasification of Occupation; NA: Not available.

Figure. Occupation of sALS patients.

ease in one of those studies ${ }^{18}$. Differences in agricultural practices could explain the discrepancy between different findings done by different authors ${ }^{16-18}$.

Occupation as a risk factor for sALS has been subjected to analysis in several studies. Some of them have associated certain work activities with an increased risk for the disease, like football players and war veterans ${ }^{19,20}$.

Others activities that have been associated with sALS risk factor are veterinarians, health workers, athletes, hairdressers, power-production plant workers and electricians ${ }^{21,22}$.

In our series, we used the International Standard Classification of Occupation (ISCO), which is a coding system that classifies jobs into occupational groups according to similarity in skill levels and specialization of tasks and duties performed.

The most represented category, within our population, was Group 9 (elementary occupations), which includes agriculture, house cleaning and masons. These occupations might be related to excessive physical activity and exposure to toxic substances ${ }^{23,24}$.

Regarding pesticides, significant increased risk estimates were reported in two studies ${ }^{25,26}$. sALS risk was associated to the exposure to cleaning solvents or degreasers, alcohols or ketones, insecticides, fertilizers, selenium, as well as for occupations potentially exposed to solvents or pesticides (farm-related occupations) ${ }^{24,27}$. To assess the potential value of these findings, they should be replicated in other studies.

The second most represented activity was Group 3, which is formed by office workers, this finding may be associated to the fact that more than $85 \%$ of patients come from urban areas, where this type of job is highly frequent. Group 7 (craft and related trade workers) represents $10 \%$ in our series and it includes industrial workers, who work with metal and plastic, shoe industry workers, plumbers and electrical workers. The type of work done by people forming this group was pointed out, in one 
study, as a risk factor for sALS ${ }^{28}$, proposing mechanical and electrical injuries, as well as metal and other toxic substances as the underlying cause.

However, so far, studies which have analyzed different risk factors like occupation, toxin exposure and excessive physical activity could not demonstrate any convincing relationship to the occurrence of the disease ${ }^{29}$, despite of being helpful to orientate the search of its cause.

As a summary of the various findings done in this study, it is possible to state that the demographic characteristics of the patients, in our series, resemble those of other studies previously published ${ }^{9-12}$. The most represented ISCO category, in our series, was elementary occupations; other fact which deserves to be mentioned is that an important proportion of patients came from rural areas; notwithstanding that these observations might be due to the fact that a referral Centre, like ours, may bias the results owed to the high low income population we assess; on the other hand it might be that this particular population is submitted to an increased still unknown, but defined, environmental risk factor which could be related to the occurrence of the disease. Therefore, further investigation in this area is needed and warranted.

\section{REFERENCES}

1. Logroscino G, Traynor BJ, Hardiman O, et al. Descriptive epidemiology of amyotrophic lateral sclerosis: new evidences and unsolved issues. Journal of Neurology, Neurosurgery and Psychiatry 2008;79:6-11.

2. Sica RE, Dubrovsky A. Esclerosis lateral amiotrófica y enfermedades relacionadas. Editorial Científica Interamericana. Buenos Aires, 2001.

3. Valdmanis ON, Pouleau GA. Genetics of familial ALS. Neurology 2008;70: 144-152.

4. Gil J, Fournalot B, Torny F, Lacoste M, Couratier P. Exogenous risk factors in sporadic ALS: a review of the literature. Rev Neurol (Paris) 2007;163: 1021-1030.

5. Frigerio R, Elbaz A, Sanft KR, et al. Education and occupations preceding Parkinson's disease: a population-based case-control study. Neurology 2005;65:1575-1583.

6. Brooks BR. El Escorial World Federation of Neurology criteria for the diagnosis of amyotrophic lateral sclerosis. Subcommittee on Motor Neuron diseases/Amyotrophic Lateral Sclerosis of the World Federation of Neurology research Group on Neuromuscular Diseases and the El Escorial "Clinical limits of amyotrophic lateral sclerosis" workshop contributors, J Neurol Sci 1994;124(Suppl):S96-S107.

7. Resolution Concerning Updating the International Standard Classification of Occupations 2008 (ISCO-08).

8. Movimiento de Internacion según Especialidades. Hospital General de Agudos José María Ramos Mejía. Ministerio de Salud - GCABA. Año 2008.
9. Bonvicini F, Vinceti M, Marcello N, Rodolfi R, Rinaldi M. The epidemiology of amyotrophic lateral sclerosis in Reggio Emilia, Italy. Amyotrophic Lateral Sclerosis 2008;9:350-353.

10. Donaghy C, Toole O, Sheehan C, Kee F, Hardiman O, Patterson V. An all-Ireland epidemiological study of MND, 2004-2005. Eur J Neurol 2009; 16:148-153.

11. Vázquez M, Ketzoián C, Legnani C, et al. Incidence and Prevalence of amyotrophic lateral sclerosis in Uruguay: a population-based study. Neuroepidemiology 2008;30:105-111.

12. O'Toole O, Traynor BJ, Brennan P, et al. Epidemiology and clinical features of amyotrophic lateral sclerosis in Ireland between 1995 and 2004. J Neurol Neurosurg Psychiatry 2008;79:30-32.

13. Werneck LC, Bezerra R, Silveira Neto O, Scola RH. A clinical epidemiological study of 251 cases of amyotrophic lateral sclerosis in the south of Brazil. Arq Neuropsiquiatr 2007;65:189-195.

14. Yoshida S, Mulder DW, Kurland LT, Chu CP, Okazaki H. Follow-up study on amyotrophic lateral sclerosis in Rochester, Minnesota, 1925-1984. Neuroepidemiology 1986;5:61-70.

15. Mitsumoto H, Przedborski S, Gordon P. Amyotrophic Lateral Sclerosis. Taylor and Francis Group, New York 2006.

16. Govoni V, Granieri E, Fallica E, Casetta I. Amyotrophic lateral sclerosis, rural environment, agricultural work in the Local Health District of Ferrara, Italy, in the years 1964-1998. J Neurol 2005;252:1322-1327.

17. Gunnarsson LG, Lindberg G, Söderfeldt B, Axelson O. Amyotrophic lateral sclerosis in Sweden in relation to occupation. Acta Neurol Scand 1991;83:394-398.

18. Furby A, Beauvais K, Kolev I, Rivain JG, Se'bille V. Rural environment and risk factors of amyotrophic lateral sclerosis: a case-control study. J Neurol 2010;257:792-798.

19. Beretta S, Carri MT, Beghi E, Chio A, Ferrarese C. The sinister side of Italian soccer. Lancet Neurol 2003;2:656-657.

20. Beghi E, Morrison KE. ALS and military service. Neurology 2005;64:6-7.

21. Weisskopf MG, McCullough ML, Morozova N, Calle EE, Thun MJ, Ascherio A. Prospective study of occupation and amyotrophic lateral sclerosis mortality. Am J Epidemiol 2005;162:1146-1152.

22. Chio A. Risk factors in the early diagnosis of ALS: European epidemiological studies. Amyotroph Lateral Scler Other Motor Neuron Disord 2000;1(Suppl 1):S13-S18.

23. Longstreth WT, McGuire V, Koepsell TD, Wang Y, van Belle G. Risk of amyotrophic lateral sclerosis and history of physical activity: a populationbased case-control study. Arch Neurol 1998;55:201-206.

24. Gait R, Maginnis C, Lewis $S$, et al. Occupational exposure to metals and solvents and the risk of motor neuron disease: a case-control study. Neuroepidemiology 2003;22:353-356.

25. McGuire V, Longstreth WT Jr, Nelson LM, et al. Occupational exposures and amyotrophic lateral sclerosis: a population-based case-control study. Am J Epidemiol 1997;145:1076-1088.

26. Park RM, Schulte PA, Bowman JD, et al. Potential occupational risks for neurodegenerative diseases. Am J Ind Med 2005;48:63-77.

27. Vinceti M, Nacci G, Rocchi E, et al. Mortality in a population with longterm exposure to inorganic selenium via drinking water. J Clin Epidemiol 2000;53:1062-1068.

28. Sutedja NA, Veldink JH, Fischer K, et al. Lifetime occupation, education, smoking, and risk of ALS. Neurology 2007;69:1508-1514.

29. Harwood CA, Mcdermott CJ, Shaw PJ. Physical activity as an exogenous risk factor in motor neuron disease (MND): a review of the evidence. Amyotrophic Lateral Sclerosis 2009;10:191-124. 